\title{
Computers in audit: servants or sirens?
}

\author{
Iain K Crombie, Huw T O Davies
}

In Greek mythology the song of the Sirens was of such beauty and promise that no sailor could resist steering his ship towards them. Instead of the promised heaven, however, the route led to disaster upon the rocks.

Audit has developed rapidly over the past three years in Britain from an activity carried out by only a few enthusiasts ${ }^{14}$ to one in which all doctors are enjoined to take part. ${ }^{5}$ Prominent among the guidance to clinicians are documents on the choice of computer systems for audit ${ }^{67}$ and several papers on audit have emphasised the role of microcomputers. ${ }^{2+89}$ There are now many commercial audit packages that not only offer help in audit but will also write discharge letters, manage waiting lists and theatre lists, and enable the computerisation of medical records for research.? The attraction of being able to combine audit with all these other activities might appear irresistible.

We argue that microcomputer based audit packages, far from offering solutions to audit problems, are more akin to the Sirens luring the unwary auditor to disaster.

\section{Fallacy of the common core of data}

Audit, patient administration systems, and clinical research may seem to have a common core of data as all collect basic demographic details and information on investigations, diagnosis, and treatment. If audit is to be performed anyway, why not collect a little extra data and achieve a great deal more? In reality, although there is a degree of overlap in the data sets collected, the differences among them are greater than the similarities. The essence of good audit is to focus on a specific topic and to collect only essential information on a sample of patients over a limited time. ${ }^{10} \mathrm{~A}$ patient administration system extends the time of data collection to include all patients and embraces a wide range of topics on which it can collect only a limited amount of data. A system of computerised case notes also surveys all patients but collects detailed information on all topics. Clinical research is in fact closest to audit and differs only in the amount of detail in which the data are collected. These two activities, however, differ in their purposes: audit is concerned with improving the quality and efficiency of medical care whereas research focuses on generating or testing hypotheses. Audit seeks to ensure that current knowledge is properly and fully used; research entails the discovery of new knowledge.

\section{Department of Epidemiology and Public Health, University of Dundee, Ninewells Hospital and Medical School, Dundee DD1 9SY Iain K Crombie, PHD, senior lecturer \\ Huw T O Davies, MSC, research fellow}

Correspondence to: Dr Crombie.

\section{Problems of computerised systems}

Collecting additional data might not seem to present much of a problem: data entry is not expensive and computers can easily handle large volumes of data. However, for each activity the amount of detail to be recorded will have to be decided, methods of recording it will have to be developed (that is, who will do it, when, and how will it be coded), and time will have to be spent recording it. Further, the development and running of a computerised system is far from straightforward. Staff will have to be trained in the use of the system and someone held responsible for the routine tasks of data entry, analysis, maintenance, and backing up the data. These difficulties will increase with the complexity of the system: each additional function or facility will bring a new set of problems, with little or no benefit for audit.

There is no doubt that routine data collection systems have an important role in the delivery of health care, and, where these systems have been established, there would be many advantages in exploiting them for audit. Yet for many audit topics it is unlikely that all the relevant data will be available in sufficient detail, and there will be other topics for which no data will have been collected. Thus it is far from clear that the effort of establishing such a system can be justified if the primary purpose is to carry out audit.

Several groups have succeeded in establishing routine data collection systems in which computers had the central role in collecting and managing the data. These groups, however, were led by enthusiasts, and it is clear that success was achieved only after months, and, in some instances years, of effort. ${ }^{248}$ The question is not whether such systems, designed and run by experts, can produce interesting results. Instead it is whether the cost and the workload arising from their widespread use by less experienced practitioners will be justified by the contribution they make to improvements in patient care.

\section{True nature of audit}

The limitation of the role which these computer systems have in audit can be clearly seen by listing the stages of an audit (figure). Developed from Fowkes'

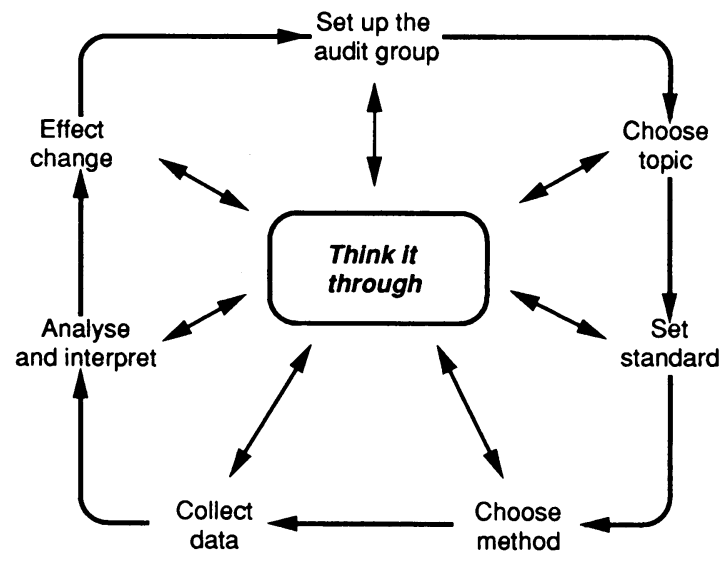

Thoughtful audit cycle

audit cycle, ${ }^{11}$ the figure casts the stages in terms of the activities to be undertaken. It shows that the stages at which computers are useful-data collection and analysis - form only a small part of the audit. It is well recognised that other stages of the cycle-setting standards and effecting change ${ }^{1213}$-pose major difficulties. The figure also shows the amount of careful thought required to carry out an audit because the stages are not simply followed in sequence but interact with each other. In fact, in the planning of an audit project it will be necessary to consider each stage of the cycle two or three times, modifying the approach and refining the design, before starting to collect data.

This interaction can be illustrated by a hypothetical example of audit in a hospice, as used recently in a 
course on medical audit run by us. An audit committee is formed, consisting of a consultant in oncology, junior staff, and nursing representatives. They decide to audit the use of opioids in managing pain caused by cancer as there is evidence from elsewhere of under use of these drugs. The choice of topic causes them to reform the audit committee to include the ward pharmacist. The standard set is that $95 \%$ of patients should be free of pain, which raises questions of which types of patients and over what time interval. The topic is amended to be more precise. It is now clear that a prospective study will have to be carried out, as case notes are unlikely to contain data on pain collected in a consistent way. The topic is again modified to refer only to new patients. The data to be collected are decided and it becomes apparent that the standard of "freedom from pain" is poorly defined and difficult to measure. The standard is modified to refer to episodes of sleep free of pain and now states that $95 \%$ of patients should have $80 \%$ of nights when they are not wakened with pain. Members of the committee now realise that they lack the skills to analyse the data and thus co-opt a statistician on to the committee.

When consideration is given to ways of effecting change, difficulties are anticipated in persuading all medical and nursing staff that controlled drugs should be used more frequently and that access to them be made easier. It is thought that strong evidence is needed that there is significant uncontrolled pain which could be alleviated by increasing the prescribing of opioids. The study is modified to specify that patients' sleep patterns should be monitored regularly by senior clinical staff, who can amend drug prescriptions when required. The audit cycle is then reentered, and the new project is subjected to similar scrutiny.

The important point abouk this exercise is that it shows how far removed an audit project is from routine data collection. Further, it shows that considerable thought is required to develop an audit project and that this can be helped by thinking through the audit cycle. Although this example is hypothetical, similar processes have clearly taken place in those published audits which have successfully improved the delivery of patient care. ${ }^{31+16}$

\section{Conclusions}

Computers undoubtedly have an important role in helping to deliver medical care. In particular, they can greatly facilitate the collection and management of accurate and relevant information. However, we have argued that, although computer systems may be valuable for some stages of audit, the major difficulties facing audit will not be solved by them. Further, because of the apparent ease with which it can be done, there is a temptation to develop the computer system to collect more data on more patients than are required for an audit. The Americans, who have much more experience in audit, have coined the term "orphan data" 2 to describe unused data which have been collected in this way. A great deal of activity may take place, but there will be little progress to the goal of audit-namely, effecting change.

Cautionary notes on the limited role of information technology have started to appear,,$^{17-19}$ but it is not clear they will be heeded. At least one health district seems to be requiring all clinical firms to record routine data on every patient contact as a basis for clinical audit. ${ }^{20}$ General practice has had a much longer experience of the widespread use of microcomputer systems than most other specialties. A recent survey of audit in general practice found that, although many collected practice activity data, the collection was poorly focused and almost half the doctors did not use the data. ${ }^{21}$ It seems likely that hospital specialties will follow the same course.

We thank the participants of the audit course for their helpful suggestions. IKC was supported by the Scottish Home and Health Department and HTOD by the Ian Mactaggart Trust and the North British Pain Association. 1 Mcllwaine G, Howat RCL, Dunn F, MacNaughton MC. The Scottish
perinatal mortality survey. BMF 1979;ii: 1103-6.

2 Gruer R, Gordon DS, Gunn AA, Ruckley CV. Audit of surgical audit Lance 1986;i:23-6

3 Fowkes FGR, Davies ER, Evans KT, Green G, Hartley G, Hugh AE, et al. Multicentre trial of four strategies to reduce the use of a radiological test. Lancet $1986 ; 1: 367-9$.

4 Ellis BW, Michie HR, Esufali ST, Pyper RJD, Dudley HAF. Development of a microcomputer-based system for surgical audit and patient administration: a review. F $R$ Soc Med 1987;80:157-61.

5 Secretaries of State for Health, Wales, Ireland, and Scotland. Working for patients. London: HMSO, 1989. (Cm 555.$)$

6 Department of Health. Medical audit: guidance for hospital clinicians on the use of computers. London: HMSO, 1990

7 Tyndal R, Kennedy S, Naylop S, Pajak F, Lattimer W, Edwards N, et al. Computers in medical audit. London: Royal Society of Medicine, 1990.

8 Dunn DC. Audit of a surgical firm by microcomputer: five years' experience. BMF 1988;296:687-91.

9 Ellis BW. How to set up an audit. BMF 1989;298:1635-7.

10 Shaw CD. Medical audit: a hospital handbook. London: King's Fund Centre, 1990.

Fowkes FGR. Medical audit cycle. Med Educ 1982;16:228-38.

12 Nelson AR. Orphan data and the unclosed loop: a dilemma in PRSO and medical audit. $N$ Engl f Med 1976;295:617-9.

medical audit. N Engl f Med 1976;295:617-9.

14 Smith $\mathrm{RB}$, Deal audich $\mathrm{CH} 1990 ; 300.65$. the accident and emergency department. $B M F 1990 ; 300: 1560-3$.

15 Colver AF. Health surveillance of pre-school children: four years' experience. BMF 1990;300:1246-8.

16 Martin AR, Wolf MA, Thibodeaeu LA, Dzau L, Brunwauld E. A trial of tw strategies to modify the test-ordering behavior of medical residents. N Engl F Med 1980;303:1330-6.

17 Hopkins A. Approaches to medical audit. If Epidemiol Community Health 1991;45:1-3.

18 Frater A, Buchan H. Physician heal thy software. Br f Hosp Med 1991;45: 47-8.

19 Mulball D. Software or soft touch? British foumal of Health Care Computing 1990;7:20.

20 Ellis BW, Sensky T. A clinician' guide to setting up audit. BMf 1991;303: 704-7.

21 Webb SI, Dowell AC, Hevwood P. Survey of general practice audit in Leeds. BMF 1991;302:390-2.

(Accepted 2 fuly 1991)

\section{THE MEMOIR CLUB}

For amateur botanists - and the same must be true of zoologists - the mainspring of their often arduous devotion to scientific research is a love of nature. By studying the lives of plants and their genetic and social relationships we amateurs learn something about the human condition and open a window into our own souls. Contemplation of the almost infinite variety of pattern in nature, whether the pattern is of structure or development or behaviour, disrupts the conventional modes of thought in which we tend to take shelter as we grow older, keeps alive a youthful sense of wonder at the fullness of life, and continues as the years pass to stretch the imagination out to barely perceived visions where hill meets sky.

But as an amateur I could never have turned to any branch of zoology that entailed killing the animals I was studying. For a time I became interested in spiders and had to kill several in the course of work, but the look of abhorrence on my 6 year old daughter's face so faithfully reflected my own revulsion that I abandoned the project immediately. Though in no way an antivivisectionist, I know that $\mathrm{I}$ could never have carried out experiments on animals myself, grateful as I am for the benefits brought to us by the physiologists and pharmacologists who do not have these qualms. Nor am I alone in the medical profession in having these reservations, as I have found.

Many years ago, for instance, a paper submitted to the $B M \mathcal{F}$ described some work on rats - not the most appealing of animals - whose manner of death seemed to me to be unnecessarily harsh. The editor, Clegg, agreed with me, and we decided to obtain the opinion of an expert adviser experienced in animal experiments. When sending him the paper I was careful to phrase the question in completely neutral terms. He also thought the method of killing them was offensive, so we rejected the paper. The adviser was the Nobel prize winner P B Medawar.

From Reap a Destiny: Divagations of a Taoist by Douglas Swinscow. Published under the BMF's Memoir Club imprint. ISBN 072790255 5. Price: Inland $£ 14.95$; abroad $£ 17.50$; USA $\$ 29.00$. BMA members: Inland $£ 13.95$; abroad $£ 16.50$; USA $\$ 27.00$. 